\title{
Barriers to Price Convergence
}

\section{Marina Glushenkova* Andros Kourtellos ${ }^{\dagger}$ Marios Zachariadis ${ }^{\ddagger}$}

This Draft: May 9, 2018

\begin{abstract}
This paper uncovers novel empirical patterns in the cross-country price mechanism using a nonlinear factor model and threshold regression analysis based on individual goods retail price data for a large panel of countries. To our knowledge, this is the first paper to find strong evidence for club convergence of retail prices. These clubs emerge due to the interaction of traded and non-traded factors. For example, countries physically closer to potential trade partners converge faster than countries in the high distance regime as long as they have low initial labor productivity or low initial income. Moreover, we find an asymmetry in the extent that arbitrage opportunities related to international trade are exploited, with low initial price regime countries exhibiting faster convergence from below than high initial price regime countries exhibit from above, consistent with less resistance to exporting than to importing due to political economy considerations. We interpret our findings as evidence of a local law of one price due to barriers to price convergence influencing the duration of the effect of price shocks.
\end{abstract}

Keywords: convergence clubs, micro prices, nonlinear factor model, threshold regression, law of one price, local convergence.

\section{JEL Classification Codes: F4}

*Nottingham University Business School China, 199 Taikang East Road, 315100 Ningbo, China, email: marina.glushenkova@nottingham.edu.cn

${ }^{\dagger}$ Department of Economics, University of Cyprus, P.O. Box 537, CY 1678 Nicosia, Cyprus, email: andros@ucy.ac.cy.

${ }_{\ddagger}^{\ddagger}$ Department of Economics, University of Cyprus P.O. Box 537, CY 1678 Nicosia, Cyprus, email: zachariadis@ucy.ac.cy. 


\section{Introduction}

This paper contributes to the long-standing debate about price convergence by investigating the existence of club convergence in prices using semi-annual micro price level data for 40 countries and 96 goods and services over the period 1990-2010. Our goal is to answer the following set of questions. Do retail prices for individual goods and services across countries globally converge to a single price or diverge? Do countries form price convergence clubs? If so, what factors determine these? To our knowledge, ours is the first study to find evidence of meaningful convergence clubs in the cross-country price mechanism. This means that there exists a tendency for prices across countries with identical structural characteristics to converge to one another if their initial prices are in the basin of attraction of the same steady-state equilibrium. We find that this tendency is induced by the interaction of traded and non-traded input components of retail prices.

At the heart of the debate about price convergence is the Law of One Price (LOP) which asserts that, as a result of arbitrage, identical goods sold in different locations will have identical prices when expressed in terms of the same currency. Empirical evidence in favor of the LOP is mixed. According to one strand of the literature, the LOP does hold in the long run, conditional on cross-country structural heterogeneity due to transport costs and other barriers to trade. During the last decade, a number of studies have utilized micro price levels to assess the rate of price convergence and understand the mechanisms that determine cross-country price convergence. This includes Crucini and Shintani (2008) using Economist Intelligence Unit (EIU) annual price level data for 1990-2005, Burstein and Jaimovich (2012) using barcode prices, and Andrade and Zachariadis (2016) who find relatively low half-lives using semi-annual EIU prices also used in our study here 11 This recent literature suggests that using micro prices with higher comparability across locations resolves estimation biases associated with the use of aggregate price indices, so that the micro-price literature finds relatively faster price convergence across countries than previous work. Our use of comparable micro-prices across countries in the current study is thus key to properly assessing international price convergence.

One particular line of empirical research departs from the linear model used in the above studies, drawing on Dumas (1992) and Sercu, Uppal, and Van Hulle (1995) who suggest the presence of threshold nonlinearities in the cross-country good price process.

\footnotetext{
1 Andrade and Zachariadis (2016) emphasize the importance of global macro shocks in driving micro-price dynamics. These are always associated with a slower response of prices than local shocks.
} 
Threshold nonlinearities arise here due to transactions costs in international arbitrage that create a "band of inaction" within which marginal cost exceeds marginal benefit from arbitrage and prices behave as a random walk. By contrast, outside the no-arbitrage band, arbitrage acts as a convergence force to the LOP. These transaction costs can be interpreted as "market frictions" capturing sunk costs of international arbitrage so that traders enter the market only when large enough opportunities arise (Dixit (1989), Krugman (1989)), or costs associated with changes in preferences and technology (O'Connell and Wei (2002)).2 Thus, most empirical studies that depart from linear models employ thresholdtype autoregressive models to uncover the "band of inaction" within which no trade takes place. These studies focused on a particular threshold regression model, namely the three regime threshold autoregressive (TAR), to uncover threshold effects of the lagged log price on log price differences when the lagged log price is above or below a particular lagged price threshold value; e.g., Obstfeld and Taylor (1997) and Choi, Murphy, and Wu (2017). The hypothesis is that, inside the band, price deviations from the LOP are persistent while above or below this band arbitrage takes place and deviations from the LOP mean-revert. The alternative hypothesis has typically been that there is no nonlinearity, so that other reasons for nonlinearities have been ignored.

While it is easy to see that the theory departing from the LOP naturally implies threshold-like structures for price convergence, the existing empirical literature is silent as to whether lack of global convergence to the LOP is associated with convergence clubs (groups of countries that converge locally but not globally) and if it is, what factors generate those clubs. We contribute to the price convergence literature by testing for convergence clubs and providing estimates of convergence rates to a Local Law of One Price (LLOP). By local, we refer to the idea that the LOP applies to meaningful subsets of countries and varies across these groups due to group-specific structural heterogeneity. If final goods are comprised of traded and non-traded inputs as in the retail pricing model from Crucini, Telmer, and Zachariadis (2005), the price level for any final good is then determined by factors pertaining to its respective traded and non-traded components. Its traded component is influenced by trade costs and the ability to exploit arbitrage opportunities, while its non-traded component

\footnotetext{
${ }^{2}$ Nonlinearities may also occur for other reasons, including heterogeneity in agents expectations because of differences in factors like risk aversion and constraints due to laws, regulations and institutions (e.g., Brock and Hommes (1997)), due to asset market imperfections (Corsetti and Dedola (2005)), search frictions (Alessandria (2009) and Alessandria and Kaboski (2011)), or endogenous currency choice in the presence of price stickiness (Gopinath (2016)). Midrigan (2007) considers a model where the "inaction bands" are not only functions of the trade cost and the elasticities of substitution but also of the volatility of the environment.
} 
by local input costs and productivity. Thus, theory would suggest that, in addition to productivity and local input costs, physical distance from potential trade partners and initial price levels might characterize different regimes. In this sense, we posit that countries which converge to different LLOPs depending on differential degrees of physical remoteness from potential trade partners, could belong in different price level regimes. Similarly, countries with differences in local input costs or productivity would be expected to form different price level regimes ${ }^{3}$ Crucini, Telmer, and Zachariadis (2005) find evidence for the empirical relevance of the retail pricing model showing traded and non-traded inputs played a role in price dispersion across Europe before the euro, while Glushenkova and Zachariadis (2016) find similar evidence after monetary unification.

Our work is closely related to Chen, Choi, and Devereux (2008) who test for $\sigma-, \beta-$, and stochastic-convergence allowing for club convergence using a clustering algorithm originally proposed by Hobijn and Franses (2000) identifying groups of converging countries based on a multivariate test for stationarity. Using data since 1890 for eleven developed economies, they find global $\sigma$ - and $\beta$-convergence for price levels occurs later and to a lesser extent than for income. Importantly, they do not find any evidence of price convergence within meaningful clubs, in contrast to what has been found in the empirical growth literature regarding income convergence. Our paper differs in several important dimensions including data and methods. Notably, we employ a large panel of disaggregate data for a large number of goods and countries at the semi-annual frequency in order to alleviate cross-sectional aggregation biases (Imbs, Mumtaz, Ravn, and Rey (2005)) . I Our work is also related to the economic growth literature that provides evidence for multiple regimes and nonlinearities in the cross-country growth process, consistent with club convergence (e.g., Durlauf and Johnson (1995), Durlauf, Kourtellos, and Minkin (2001), and Tan (2010)). Given this literature, there would be limited scope for investigating price convergence clubs if these were driven by economic development. However, as shown by Chen, Choi, and Devereux (2008), income and price levels convergence differ in a number of ways and factors determining price regimes can be distinct from those determining income ones.

We start by investigating the existence of convergence clubs using the nonlinear timevarying heterogeneous factor model proposed by Phillips and Sul (2007, 2009). An appealing feature of this nonlinear factor model is that it distinguishes between economies that have

\footnotetext{
${ }^{3}$ In the latter case, however, price level regimes would plausibly be similar to income level regimes that have been the focus of the relevant growth literature.

${ }^{4}$ Moreover, our data do not suffer from the type of temporal aggregation shown by Taylor, Peel, and Sarno (2001) to introduce severe biases in the estimation of convergence parameters.
} 
converged and economies that are converging, by explicitly addressing the question of invariance of the time-series process for prices. As argued by Phillips and Sul (2009), this methodology circumvents various problems associated with the validity of conventional price convergence tests. Using the concept of "relative" convergence, we find ample evidence of lack of global convergence in the form of convergence clubs for nearly all 96 goods. This heterogeneity in the cross-country price process generally carries over to the industry level. Interestingly, the results suggest that the latent factor that determines these clubs is associated with differences in the traded and non-traded components of the goods.

Next, we examine the determinants for convergence clubs using the threshold regression model that allows us to study concepts of conditional $\beta$-convergence whereas "relative" convergence is akin to conditional $\sigma$-convergence. Threshold regression generalizes the linear regression by classifying the observations into regimes each of which obeys the same linear model on the basis of an observed threshold determinant as opposed to the methodology of Phillips and Sul (2009) that assigns observations into clubs on the basis of a latent factor. The threshold parameter is treated as an unknown parameter, estimated together with the other parameters of the model. In this context, by club convergence we mean the presence of regime-specific conditional $\beta$-convergence so that differences in the degree of price convergence between regimes are interpreted as evidence of conditional $\beta$-convergence within rather than across regimes. We consider threshold variables influencing the traded and nontraded components of a final good. Using income or labor productivity as threshold variables, we ask whether poorer countries behind the frontier tend to exhibit faster convergence via the non-traded component of final prices, consistent with the Balassa-Samuelson hypothesis. Using physical distance as a threshold variable, we ask if countries with smaller distance from potential trade partners exhibit relatively faster price convergence via the traded inputs channel. Similarly, using initial prices as a threshold variable we ask whether countries more able to exploit arbitrage opportunities $5^{5}$ exhibit faster price convergence via the traded inputs channel. Our results are informative about potential factors behind international market segmentation.

We find no evidence of global conditional $\beta$-convergence, yet importantly, we find strong evidence for club convergence as implied by the presence of local $\beta$-convergence of countries within meaningful groups in our sample. Countries are organized into price convergence

\footnotetext{
${ }^{5}$ We expect less resistance to exporting (the case of initially cheap countries) than to importing (the case of initially expensive countries) so that resistance to international trade and the resulting ability to arbitrage away price differences could be asymmetric, with countries in the low initial price regime facing less resistance and thus better able to exploit arbitrage opportunities via international trade.
} 
clubs according to traded factors such as physical distance from potential trade partners and non-traded factors such as labor productivity, local input costs and economic development. We find that clubs are formed due to the interaction of these traded and non-traded factors. Lower trade costs are conducive to price convergence for countries that have the non-traded Balassa-Samuelson catch up process operating in full force given low initial productivity, labor cost or income. This might be due to the fact that at an early stage of development, industries stand to gain more from proximity to potential trade partners whereas this does not appear to matter for industries in advanced economies producing highly differentiated products whose demand is not as sensitive to higher trade costs as compared to exports of less differentiated goods from less developed countries.

Being behind the frontier is conducive to price convergence for countries with small physical distance from potential trade partners as compared to countries in the high-distance regime, consistent with economic growth theory models where the growth advantage of initial economic backwardness is greatly facilitated by the ability to trade more cheaply. We also find an asymmetry in the extent that arbitrage opportunities related to international trade are exploited, with low initial price regime countries exhibiting faster convergence from below than high initial price regime countries exhibit from above. This can be explained by lower resistance to exporting in initially cheap countries than to importing in initially expensive countries where some local producers and workers stand to lose out, so that resistance to international trade and the resulting ability to arbitrage away price differences is rendered asymmetric due to political economy considerations. Finally, convergence is significantly faster for countries with low initial productivity (income) as compared to high initial productivity (income) countries, in the case of countries with high control of corruption but not for those associated with low corruption control. This suggests the catch up process operating via the Balassa-Samuelson channel is present for countries successful in controlling corruption via appropriate institutions but not for those with low control of corruption.

The rest of the paper proceeds as follows. In the next section, we describe the data we use. Section 3 describes the nonlinear factor model of prices that we use to identify price convergence clubs, and reports the corresponding results. Section 4 describes the threshold regression methodology and discusses the findings. Section 5 briefly concludes. 


\section{Data}

The retail price data are from the Economist Intelligence Unit (EIU) and described in the online appendix (pages 2 to 6) of Andrade and Zachariadis (2016) along with a discussion of issues related to sample selection and reliability of these data. The price for each item is collected for supermarkets or chains, and for mid-priced outlets. To alleviate possible measurement error, we average prices across stores where possible. The EIU survey covers 140 cities in 90 countries but availability varies across locations. In order to analyze price convergence across countries, we choose the city with the largest available set of data for each country. Moreover, to be able to apply the Phillips and Sul (2007) analysis we utilize only prices of items that are available in all time periods. For comparability, we use goods available in more than two-thirds of the countries. We end up with a sample of 96 unique product items in 40 countries available semiannually from $1990 \mathrm{H} 1$ to $2010 \mathrm{H} 1$. A list of the 96 product items is available in Table A1, while the 40 countries are shown in Table A3.

We organize goods in groups using industry classification ISIC rev 2. Our price dataset contains different numbers of items for different industries, with the largest number in food manufacturing (a total of 41 items) and the smallest number of items in tobacco manufactures (just 3 items). To allow sufficient cross-industry variation, we exclude countries with less than two thirds of the goods of an industry available. At the same time, we exclude industries with small numbers of goods (less than 5 items). The excluded industries are Tobacco Manufactures (3 items), Soft Drinks (4 items), Manufacture of Motor Vehicles (4 items), and Electricity, Gas and Steam (4 items). Similarly, we exclude Manufacture of Alcohol Beverages, Transport, Storage and Communication, and Real Estate, since retention of these would lead to the exclusion of nine countries 6 with insufficient data for these items.

In Section 4 we utilize data for control of corruption and democratic accountability to detect the institutional determinants of price convergence. These data were obtained from the International Country Risk Guide from the PRS group for 1990-2010. For these variables, higher score means lower risk. As a measure of initial economic performance of the country we use lagged log real GDP per capita and lagged labor productivity data, obtained from the Penn World Tables 7.1 for 1989-2010. We calculate average distance from each city to all other cities in the sample as a measure of geographic isolation from potential trade partners. We also utilize data for labor cost obtained from the EIU for 1990-2010, available for only 31 countries. More details about all data are given in Table A19 of the Online Appendix.

\footnotetext{
${ }^{6}$ Canada, Germany, Guatemala, Kenya, Mexico, New Zealand, Philippines, Poland and the U.S..
} 


\section{Price convergence clubs}

\subsection{A Nonlinear factor model for prices}

We assume that for each good $\mathrm{j}$ the logarithm of prices $p_{i j t}$ in country $i$ at time $t$ is described by a nonlinear factor model proposed by Phillips and Sul (2007). This model includes a price growth component and a time varying idiosyncratic component that allows for general heterogeneity across countries and over time and takes the form of

$$
p_{i j t}=\delta_{i j t} \mu_{j t}
$$

where $\mu_{j t}$ is a good specific common trend, which can be deterministic and/or stochastic, with time-varying factor loading coefficients $\delta_{i j t}$ that include both country and good specific permanent and transitory components.7 $\delta_{i j t}$ is a vector of weights that describes the transition path of good $j$ in economy $i$ to the common steady state price growth path determined by $\mu_{j t}$. Put differently, these weights can be interpreted as the price gap between the price $p_{i j t}$ and the common trend $\mu_{j t}$.

\subsection{Relative convergence}

Following Phillips and Sul (2007) we employ the concept of "relative" long-run equilibrium or convergence, which means that two series share the same stochastic or deterministic trend elements in the long run, so that their ratio eventually converges to unity. Relative price convergence for each good $j$ is defined as $p_{i j t+k} / p_{l j t+k} \rightarrow 1$, as $k \rightarrow \infty$ for any pair of countries $i \neq l$ or equivalently $\delta_{i j t+k}=\delta_{j}$ as $k \rightarrow \infty$. Relative convergence is related to standard convergence definitions used in the empirical growth literature (e.g., Bernard and Durlauf 1995, 1996) and Evans and Karras (1996)). For instance, while relative convergence in the discrete time series implies price growth convergence in the long-run, it does not generally imply level convergence. When the weight $\delta_{i j t}$ converges faster than the divergent rate of the common component $\mu_{j t}$ in equation (1), then relative convergence implies absolute or level convergence, but otherwise relative convergence does not imply level convergence.

The relative convergence can be tested using the log t test, which is based on an auxiliary

\footnotetext{
${ }^{7} \delta_{i j t}$ is assumed to have an additive panel model, $\delta_{i j t}=\frac{g_{i j t}+\varepsilon_{i j t}}{\mu_{j t}}$, where $g_{i j t}$ and $\varepsilon_{i j t}$ are the permanent and transitory components, respectively.
} 
least-squares regression that involves the logarithm of time as a regressor.

$$
\log \left(\frac{D_{1 j}}{D_{t j}}\right)-2 \log \log t=\lambda_{0 j}+\lambda_{1 j} \log t+u_{t j}
$$

where $D_{j t}=\frac{1}{N} \sum_{i=1}^{N}\left(h_{i j t}-1\right)^{2}$ is the sample transition distance and $h_{i j t}=\delta_{i j t} / N^{-1} \sum_{i=1}^{N} \delta_{i j t}$ is the relative transition curve for $t=[r T],[r T]+1, \ldots, T$ with some trimming percentage $r>0.8$ For the null of global convergence the test takes the form of a sign restriction on the slope coefficient of $\log t, H_{0}: \lambda_{1 j} \geq 0$ vs. $H_{1}: \lambda_{1 j}<0$, which can be tested using a conventional one-sided t-test constructed with a heteroscedasticity and autocorrelationconsistent (HAC) estimator from the residuals of equation (2).

The magnitude of the coefficient $\lambda_{1 j}=2 \alpha_{j}$ measures the convergence speed of $\delta_{i j t}$ since the parameter denotes the rate at which the cross-sectional variation across the transition paths decays to zero over time $9^{9}$ Under the condition that the common component $\delta_{i j t}$ follows a random walk with drift or a trend stationary process, we have growth convergence if $0 \leq \lambda_{1 j}<2$ and level convergence in $\log$ prices if $\lambda_{1 j} \geq 2$.

\subsection{Club convergence procedure}

Rejecting the null of global convergence leaves open the possibility of convergence within some clubs of countries. Following Phillips and Sul (2009), we employ the above test sequentially in subgroups of observations to uncover multiple price regimes. The procedure comprises of four steps: (1) observations are sorted from the latest to the earliest time period of the panel; (2) using the log t test, a primary convergence club is formed against which other countries may be compared; (3) sieving through countries one at a time to check for possible membership of the primary convergence club using the log t regression; (4) repeat steps 2 and 3 and if no further convergence clubs emerge, classify the remaining observations as displaying divergent behavior. In the Online Appendix we provide a detailed description of this clustering procedure.

\footnotetext{
${ }^{8}$ The presence of divergence from $\mu_{j t}$ is reflected in the transition paths $h_{i j t}$. For example, in the case of global convergence, the price of good $j$ in all countries moves towards the same trend, $h_{i j t} \rightarrow 1$ for all $i$ as $t \rightarrow \infty$ and the cross-sectional variance of $h_{i j t}$ converges to zero so that the sample transition distance $D_{j t} \rightarrow 0$, as $t \rightarrow \infty$. By contrast, when an economy diverges from others the transition path can measure the extent of the divergent behavior and assess whether or not this is transient.

${ }^{9}$ To see this, note that under the null of growth convergence, Phillips and Sul (2007) showed that the (sample) mean square transition distance $D_{j t}$ converges to $A /(\log (t))^{2} t^{2 a}$, where $A>0$ is a positive constant. This yields auxiliary equation 22.
} 


\subsection{Results}

\subsubsection{Price convergence clubs}

We first document the substantial evidence for lack of global convergence and provide evidence for club convergence by investigating 96 individual goods. Table A1 in the online appendix presents results for the log t-test and for the club convergence procedure described in sections 3.2 and $3.3{ }^{10}$ The first column of Table A1 shows the global convergence coefficient for the whole sample of countries. We find that the null hypothesis of global convergence is rejected for 92 of the 96 goods.11 In the next four columns of Table A1 we present results of the local convergence coefficients for each club. Our results show there exist up to four convergence clubs and that this number varies across goods ${ }^{12}$ For some goods there is a set of countries that do not form any club. We label such subsets of countries for particular goods as divergent, and report the estimated coefficient for such divergent groups of countries in the last column of Table A1. Using the definition of relative convergence, for the majority of goods we find evidence for price growth convergence within clubs since $0 \leq \lambda_{1 j}<2$. Price level convergence occurs only within the third club and for merely three goods: "White rice", "Tea bags" and "Socks, wool mixture", for which the third club is comprised of just two countries ${ }^{13}$

Next, we qualify the above convergence clubs in three alternative ways. First, in the first column of Table A2, we present average prices by good across all countries in the sample, followed by average prices across countries within each club in the remaining columns of the table. The first club is characterized by the highest price level for each good, the second club by the second highest price and so on. Hence, in what follows, we refer to the first, second, third, and fourth clubs as high-price, medium-price, low-price, and cheap clubs, respectively. Second, in Table A3 we present the frequency of belonging to each club for each country, i.e., the share of goods for which the country lies in the high-, medium-, low-price, and cheap clubs. Developed economies such as Denmark, Germany, Finland, Spain, Switzerland,

\footnotetext{
${ }_{10}$ Phillips and Sul (2007) suggest $r=0.3$ for the trimming percentage and provide finite sample evidence that the log t test has good properties even for samples smaller than 50 time-series observations.

${ }^{11}$ The exceptions are "Personal computer", "Peanut or corn oil", "Potatoes" and "Olive oil". For "Personal computer", $\lambda_{1 j}$ exceeds two thus we can infer that price level, not just price growth, convergence occurs.

${ }^{12}$ The fourth club exists for nine items: "Peas, canned", "Instant coffee", "Dry cleaning, trousers", "Laundry detergent", "Toothpaste with fluoride", "Men's business shirt", "Laundry", "Kodak color film", and "Razor blades". For "razor blades" we actually find a fifth club but opt to ignore this in the Tables since it does not arise for any other good or service in our sample.

${ }^{13} \mathrm{~A}$ detailed description of convergence club classifications for each good is available upon request.
} 
Norway, Belgium, Luxembourg, Australia, Japan, France, UK, Italy, Austria, Sweden, and the US lie in the high-price club for the great majority (for more than $60 \%$ ) of the goods while lying in the low-price club for less than ten percent of the goods. Figure A1 shows a heatmap for these shares for each country, where color defines club (blue for the high-price club, orange for the medium-price club, green for the low-price club, red for the cheap club, and grey for the divergent group) and depth of color represents frequency of belonging in that club. Third, in Table A4 of the Online Appendix we take a closer look at the high-price club, distinguishing between low, medium, and high income countries forming the first club, and present average prices over the period 1990-2010 across the subset of countries in each of these three income groups for each good. We observe that average prices vary substantially for some goods within the same club depending on income group.

\subsubsection{Industry level analysis}

We now discuss our findings using aggregated prices at the industry level as a way to summarize the information across the various goods. This type of analysis will also allow us to discern whether convergence patterns observed at the individual good level carry over to the industry level. In particular, we aggregate prices up to the industry level and proceed to define clubs for eight separate industries. We organize goods in groups using industry classification ISIC rev 2, calculate the median price across goods in each industry for every country, and use these data to define clubs at the industry level. Then, as in the good level analysis, for each industry we test for global convergence and club convergence.

Table 1 shows that the industry level results are generally consistent with the goodlevel analysis. Specifically, while the null hypothesis of global convergence is rejected for all industries, we do find evidence of club convergence. For half of the industries, the maximum number of formed clubs equals two (manufacture of food, textile, chemicals and metal products), and for other industries this number equals three (agriculture, paper products, hotel and restaurants, and other services). Moreover, for agriculture and manufacture of paper products there is a set of countries that do not form any club with any other country, thus we also have a divergent group for these industries 14

The aggregation at the industry level enables us to assess the transition dynamics graphically using the relative transition curve $h_{k h t}$ for club $k$ and industry $h$ as defined

\footnotetext{
${ }^{14}$ In the appendix, Figure A2 presents in map form the set of countries in each convergence club by industry and Table A5 provides a detailed description of the convergence club classification for each industry.
} 
in section $3.2{ }^{15}$ While these curves may exhibit heterogeneity across countries in the shortrun, they allow for convergence in the long-run. In particular, a transition curve measures the price behavior of club $k$ for industry $h$ in relation to other clubs, and at the same time describes the relative departures of club $k$ from the common steady-state price growth path ${ }^{16}$ Figure 1 presents the transition path across the countries forming each club for each industry over the period 1990-2010. Overall, we find no evidence of global convergence, since we do not observe monotonic convergence to unity for all three clubs for any industry. On the contrary, there is an apparent divergent path for clubs at the end of the period. The transition curves in Figure 1 also show that the first club, irrespective of industry, includes countries with relatively higher prices, while the second and third clubs have smaller prices. For some industries, countries forming different clubs have similar initial states, e.g., agriculture (the second and third club), manufacture of food (the first and second club) and hotel and restaurants (the first and second club), but exhibit transitional divergence starting at some later point in time. For other industries like manufacture of textile or community, social and personal services, transitional divergence appears from the beginning of the period. Interestingly, for most industries, clubs are characterized by converging transitional paths till the middle of the period after which transition paths start to diverge. These time series patterns could then be used to identify factors behind the existence and formation of clubs, e.g., due to specific physical or technological events related to certain industries, that occur at some point in time and affect countries and industries differently.

The convergence clubs formed at the industry level generally appear to share the same characteristics as the ones formed using the individual good level data. For example, the first club is always associated with the highest average price and the third club with the lowest price, as we show in Table A6 of the Online Appendix where we present average prices over the countries and period under study, for each industry in each club. However, when we distinguish between low, medium, and high income countries that form each club we have identified, we now see that average prices over the period 1990-2010 across countries in each of these three income groups for each industry do not have a clear relation with income. For some industries, price convergence clubs are highly associated with country income level while it is clearly not the case for other industries. Figure A3 shows the relationship between average prices and average (over the period of study) real GDP per capita for each of the

\footnotetext{
${ }^{15}$ The average transition curve for each club $k$ and each industry $h$ is calculated as $\widehat{h}_{k h t}=N_{k}{ }^{-1} \sum_{i=1}^{N_{k}} h_{i h t}$, where $h_{i h t}=p_{i h t} / N^{-1} \sum_{i=1}^{N} p_{i h t}$.

${ }^{16}$ Following Phillips and Sul (2007, 2009) we first use the Whittaker-Hodrick-Prescott smoothing filter to remove the business cycle component before we apply the log t test.
} 
eight industries, marking different clubs by different colors; blue is for the first club, orange for the second club, and green for the third club. For some industries like agriculture and social and personal services, price convergence clubs are highly associated with country income level, while it is clearly not the case for other industries, e.g., manufacture of food or chemicals. We infer that income might play a role in the formation of different clubs for certain types of goods, and investigate more systematically the role income and other factors play in determining price convergence clubs in the next section.

Next, we investigate the factors that sort countries into price convergence clubs using threshold regression.

\section{Determinants of convergence clubs}

\subsection{Threshold regressions and club convergence}

While the nonlinear factor model in equation (1) allowed us to identify convergence clubs using weak assumptions, it did not allow us to identify the sources of this heterogeneity as this is latent. To do so, we use a threshold regression model, classifying countries into price convergence clubs depending on whether the observed value of a threshold variable is above or below a sample split value estimated from the data. We use threshold variables $q_{s i t}$, $s=1, \ldots, p$ that relate to the non-traded and traded components of final goods prices. For the non-traded component, we use initial log real GDP per capita, initial labor productivity, and control of corruption and democracy, while for the traded component we use physical distance and initial prices. The first set of threshold variables, helps us examine whether poorer countries behind the technology frontier tend to exhibit faster convergence leading to price convergence via the non-traded component of final prices in line with the Balassa-Samuelson hypothesis. The second set of threshold variables helps us examine whether countries with smaller distance from potential trade partners or more able to exploit arbitrage opportunities due to lower resistance to trade, exhibit relatively faster price convergence via the traded inputs channel.

Using the growth of price in period $t$ for good $j$ in country $i, g_{i j t}=p_{i j t}-p_{i j t-1}$, we specify the following threshold model for a panel of semiannual prices for 96 goods from 
1990 to 2010 across 38 countries 17

$$
g_{i j t}=\left(\beta_{s 1} p_{i j t-1}+\pi_{s 1}^{\prime} z_{i t}\right) I\left(q_{s i t} \leq \gamma_{s}\right)+\left(\beta_{s 2} p_{i j t-1}+\pi_{s 2}^{\prime} z_{i t}\right) I\left(q_{s i t}>\gamma_{s}\right)+\varepsilon_{i j t}
$$

where $I(\cdot)$ is an indicator function with $I\left(q_{s i t} \leq \gamma_{s}\right)=1$ if $q_{s i t} \leq \gamma_{s}$ and $I\left(q_{s i t} \leq \gamma_{s}\right)=0$ if $q_{s i t}>\gamma_{s} . \gamma_{s}$ is the scalar threshold parameter or sample split value, $p_{i j t-1}$ is the lagged price level, $q_{s i t}, s=1, . ., p$, are threshold variables, and $z_{i t}$ is a vector of determinants including traded and non-traded variables as well as country, good, and time dummy variables. The term $\varepsilon_{i j t}$ is the regression error. The slope coefficients $\beta_{s 1}$ and $\beta_{s 2}$ are related to the idea of conditional $\beta$-convergence or "catching up" in terms of prices, i.e., the higher the initial absolute price level the lower the price growth rate. Specifically, we obtain club convergence when we have conditional $\beta$-convergence in each regime, that is, $\beta_{s 1}<0$ and $\beta_{s 2}<0$. Moreover, when $\delta_{s} \equiv\left(\beta_{s 1}-\beta_{s 2}, \pi_{s 1}-\pi_{s 2}\right)^{\prime}=0$ the threshold regression model (3) nests the linear model, which Chen, Choi, and Devereux (2008) use to test for $\beta$-convergence. The statistical theory for threshold regression is provided by Hansen (2000) who proposed a concentrated least squares method for the estimation of the threshold parameter.

Our test for club convergence involves testing for the presence of threshold effects and unit roots. First, we test for threshold effects using the hypothesis $H_{0}: \delta_{s}=0$ vs. $H_{1}: \delta_{s} \neq 0$, i.e., the null hypothesis of a linear model (no threshold effects) against the alternative of a threshold regression model. To do so, we use a heteroscedasticity-autocorrelation consistent Lagrange multiplier (LM) test and compute the p-values by a bootstrap method proposed by Hansen (1996). Second, we test whether the countries converge or diverge using a threshold autoregressive unit root test proposed by Caner and Hansen (2001) and extended for the panel-data model by Beyaert and Camacho (2008). In model (3), if $\beta_{s 1}=\beta_{s 2}=0$ then we say that the countries diverge. If both parameters are negative, then we have club $\beta$ convergence for both regimes. If the countries converge under one regime but not the other then partial convergence occurs. We apply the above tests sequentially, testing for threshold effects and unit roots within each subsample.

\footnotetext{
${ }^{17}$ Hong Kong and Singapore are excluded due to threshold variables's data unavailability. The sample falls to 31 countries in models with labor cost as threshold variable due to data unavailability.
} 


\subsection{Evidence from threshold regression models}

\subsubsection{Testing for threshold effects and unit roots}

Consistent with our evidence from the non-linear factor model, we investigate the presence of up to four convergence clubs using our baseline threshold model that includes initial prices as well as country-, good-, and time-fixed effects as explanatory variables in Table 2. The first two columns of Table 2 describe the threshold variables that define the threshold regression models. In particular, level 1 threshold variables $\left(q_{1}\right)$ are used in the two-regime model while level 2 threshold variables $\left(q_{2}\right)$ are used in the second-level of the four-regime model. The next six columns present the estimated threshold parameters and the corresponding $95 \%$ confidence intervals for the two-regime and four-regime models. The results of the threshold and unit root tests are presented as superscripts to the threshold estimate by a significance star and dagger, respectively. The last column reports the Akaike criterion (AIC).

We start by documenting the global divergence of prices, emerging due to the interaction of traded and non-traded factors in the form of threshold effects. Using sequential testing for the presence of threshold effects as in Hansen (1999), we uncover the presence of four regimes or clubs in almost all models, rejecting the linear model at the $1 \%$ in most cases, and at the $5 \%$ level in some cases. The one exception is when democracy is used as a threshold for both levels. However, even in this case we find strong evidence for a three-regime model. We also reject the unit root null in the context of the threshold regression in all cases at the $1 \%$ level. According to the AIC, the strongest evidence for a threshold split occurs with distance used as a threshold. The top three models with the lowest AIC values use democracy/distance, distance/productivity, and distance/income as level 1/level 2 threshold variables. The second best model, e.g., organizes countries into four clubs: (C1) distance below 8.798 and productivity below 10.861; (C2) distance below 8.798 and productivity above 10.861; (C3) distance above 8.798 and productivity below 10.127; and (C4) distance above 8.798 and productivity above 10.127. The distance threshold value 8.798 corresponds to Turkey, the 18th least distant country in our sample. The initial productivity threshold values 10.861 and 10.127 correspond to Spain and Mexico in 1997, the 16th and 21st most productive country in our sample in 1997, respectively.

Two important issues ought to be discussed further. First, the sequential testing strategy for uncovering multiple regimes raises the question whether the results are sensitive to the

order of the threshold variables used at level 1 and level 2. We address this issue by 
considering both possibilities and selecting to present in our baseline results in Table 2 the best model according to AIC. For completeness we also present the alternative specifications in Table A7 of the Online Appendix that show that the results are substantively the same. Second, the confidence interval for the second level threshold parameters appears to overlap in some cases. This suggests that some of the regimes might not be substantially different to one another due to the presence of high uncertainty in the estimation of threshold parameter ${ }^{18}$ In Table A8 of the Online Appendix, we illustrate the difference between the regimes by presenting the median prices for each of the four regimes that correspond to Table 2 in two ways: (i) as defined by the estimated threshold parameters (i.e., allowing for misclassification) and (ii) below and above the confidence intervals (i.e., not allowing for misclassification). We find that the four regimes are generally distinct even if we allow for misclassification.

\subsubsection{Local convergence rates}

Next, in Table 3, we present the estimated $\beta$-coefficients for each club corresponding to the threshold regression models in Table 2. The first column orders threshold models according to their AIC values and the next two columns describe their corresponding threshold variables. The next eight columns show estimates of the $\beta$-coefficients and corresponding speeds of price convergence within each club ${ }^{19}$ The speed of convergence shows the percentage semi-annual movement of the country to its local steady state relative to the remaining distance 20 The last column reports the AIC value. We note that we only present unique threshold regression models chosen by AIC. That is, for each pair of threshold variables $q_{1}$ and $q_{2}$ in Table 2 , the sequential testing procedure gives rise to two four-regime threshold models depending on the order with which the threshold variables were chosen to split the sample. We select the model that yields the lowest AIC value and present it in Table 3. This limits the number of models to 21 . Consistent with theories on multiple steady states, we find strong evidence of club convergence in line with our earlier unconditional results based on the nonlinear factor model. The $\beta$-coefficient is always estimated to be negative and strongly significant, implying the presence of club $\beta$-convergence in all regimes. This finding holds regardless of

\footnotetext{
${ }^{18}$ It is worth noting that the decision to split for four regimes cannot be based on standard inference due to the so-called Davies problem, that is, the threshold parameter is not identified under the null hypothesis. Hence, we use a bootstrap threshold test proposed by Hansen (1996) that overcomes this problem.

${ }^{19}$ In Table A9 we report the test of equality of $\beta$-coefficients for each pair of regimes in each model.

${ }^{20}$ We calculate the speed of convergence using the coefficient for the initial price level in equation (3): $-\left(1-e^{-\lambda_{k} t}\right)=\beta_{k}$, for regime $k=1,2$ and $t=1$, where $\lambda_{k}$ denotes the speed of price convergence.
} 
the choice of threshold variable. Below, we discuss our remaining theory-relevant findings. ${ }^{21}$

Findings from models 2 and 3 in Table 3 are of particular theoretical interest as these account for the effect of traded (via distance) and non-traded (via labor productivity or income) components on price convergence. These are ranked as the 2 nd and 3rd best models according to the AIC. First, based on model 2 with distance and initial labor productivity as thresholds, countries in the low distance regime converge faster than those in the high distance one as long as they have low initial productivity. This suggests lower distance-related trade costs are conducive to price convergence only for countries that have the non-traded Balassa-Samuelson catch up process operating in full force given low initial productivity levels. This might be due to the fact that at an early stage of development, industries stand to gain more from proximity to potential international trade partners whereas this does not appear to matter for industries in advanced economies. This plausibly relates to the fact that the latter produce differentiated products whose demand is not as sensitive to higher transport costs as compared to exports of less differentiated goods from less developed countries. The latter type of goods is characterized by relatively high demand elasticities so that the degree of distance-related trade costs relative to other potential exporters or domestic producers in a given destination market would play an important role in this case.

Second, for model 2 in Table 3, we also find that within the low distance regime, countries with low initial productivity converge significantly faster than those in the high productivity regime. In the high-distance regime, implied convergence is not significantly higher in the low productivity regime as compared to the high productivity one. This suggests, again, an interaction between the non-traded and traded channels via which price convergence occurs. Being behind the frontier is conducive to price convergence, presumably via the Balassa-Samuelson channel, for countries with relatively small physical distance from potential trade partners that have easier access to international trade but not for countries in the high-distance regime. This finding implies that the growth advantage of initial economic backwardness is facilitated by the ability to trade more cheaply. It points to theories where trade is assigned a key role as facilitator of economic growth which in turn leads to faster price convergence rates for initially backward economies as they catch up to the frontier.

The finding that price convergence depends on the interaction between the traded and non-traded channels persists when we replace the level 2 threshold variable initial productivity with initial income (model 3 in Table 3). Countries in the low distance regime

\footnotetext{
${ }^{21}$ As AIC values are for the most part close to each other, we use the AIC merely as a guidance for the relative strength of each model, emphasizing theory-relevant results.
} 
converge faster than those in the high distance one as long as they have low initial income. We also find that convergence is faster in the low-income regime as compared to the high-income one irrespective of whether a country lies in the low or high distance regimes. However, the difference in the speed of convergence coefficients is much greater for low versus high income countries in the low distance regime (0.151 versus 0.065$)$ as compared to within the high distance regime (0.090 versus 0.070 respectively for low and high income regime countries). The implication is that poorer countries behind the frontier tend to exhibit faster inflation leading to price convergence, consistent with the Balassa-Samuelson hypothesis according to which prices increase (and thus converge) faster in poorer countries as they catch-up by growing faster. This form of price convergence occurs via the non-traded component of final prices. We find similar evidence consistent with this notion in other threshold models with initial income or labor productivity as first or second level threshold variables. The typical finding from such models (models 2, 3, 7, 8, 9, and 11 to 16) is that countries in the low initial income or productivity regimes are associated with higher implied convergence than those in the respective high regimes.

Moreover, based on the model with distance and initial prices as first and second thresholds respectively (model 10 in Table 3), countries in the low distance regime tend to converge faster than those in the high distance one irrespective of initial price regime. The finding that the low distance regime is associated with faster implied convergence than the high distance one is quite common amongst the models we consider with distance as level 1 or level 2 threshold variable (models 1,2, 3, 5, 6 and 10) in Table 3. Importantly, based on model 10, countries in the low initial prices regime converge faster than those in the high initial prices regime, irrespective of whether they are in the low or high distance regime. In fact, looking at other models with initial prices as second threshold variable (such as models 11, 13, 18, 19 and 21 in Table 3) we see that the coefficients of initial prices are always higher (and significantly so, except for model 21 in the high regime) for low initial price level regime countries as compared to high-regime ones. This implies that countries in the low initial price regime exhibit faster catch up than those in the high initial price regime. That is, there appears to be an asymmetry in the extent that arbitrage opportunities related to international trade are exploited, with low initial price regime countries exhibiting faster convergence from below than high initial price regime countries exhibit from above. This could be related to lower resistance to exporting in initially cheap countries than to importing in initially expensive countries where some local producers and workers stand to lose out. Thus, resistance to international trade and the resulting ability to arbitrage away price differences would be asymmetric, with countries in the low initial price regime facing less 
resistance and thus better able to exploit arbitrage opportunities via international trade.

Furthermore, the results in models 11 and 13 are of particular theory interest as these models capture the effect on price convergence of two variables in each case (initial prices versus productivity or income) that map onto the respective traded versus non-traded components. In model 11 (model 13) with initial productivity (income) and initial prices as threshold variables, countries in the low productivity (income) regime converge faster than those in the high productivity (income) regime irrespective of the initial price regime they lie in, and countries with lower initial prices converge faster than countries with high initial prices irrespective of whether a country lies in the low or high productivity (income) regime. This is consistent with a retail pricing model where final goods prices have a non-traded and traded component related to productivity (or income) and initial prices respectively.

In addition, the institutions-related variable control of corruption appears to be conducive to price convergence. This is evident in model 4 in Table 3 where we use control of corruption with democracy as first and second threshold variables respectively, and in model 5 where we use control of corruption and distance as first and second thresholds. Using control of corruption and initial productivity (income) as first and second threshold variables respectively in model 7 (model 14) in Table 3, convergence in the high control of corruption regime is higher than in the low regime as long as the country has low initial productivity (income). Interestingly, for the high but not for the low control of corruption regime, convergence is significantly faster for low initial productivity (income) as compared to high productivity (income) countries. This suggests that being behind the frontier is conducive to price convergence, presumably via the Balassa-Samuelson channel, for countries successful in controlling corruption but not for those with low control of corruption. In the model with control of corruption and initial prices as threshold variables (model 19 in Table 3), countries with high control of corruption converge faster as long as they have low initial prices. Thus, control of corruption is likely to affect the ability to arbitrage away existing price differences. We would expect that countries with higher control of corruption can more readily rip the benefits of international trade and as a result would tend to exhibit relatively more rapid price convergence. Higher values of this variable could also be associated with higher competition in the local market that in turn reinforces price convergence. The basic finding that control of corruption facilitates convergence comes out in model 20 as well, where corruption control enters as both a first and second level threshold variable.

Finally, we find that the best model according to the AIC is the one that splits with 
democratic accountability and distance. We find that convergence in low democracy regimes is greater than in high democracy regimes irrespective of distance regime. Moreover, within the low democracy regime, countries with smaller distance from potential trade partners converge faster. Typically, in the models with democratic accountability as first threshold variable (models 1, 17 and 18) or as second threshold variable (models 4, 8, 9 and 17) reported in Table 3, convergence in the low democracy regime is higher than in the highdemocracy regime. Models 8 and 9 with initial productivity or income as the respective first threshold and democracy as second threshold variable, shed some light into this apparent puzzle. For these models, the result that low democracy leads to convergence holds only for the low initial productivity or for the low income regime and is not the case for high productivity or rich countries. The explanation could lie in political pressures that limit Central Bank independence and lead to more expansionary monetary policies resulting in higher inflation in initially backward (proxying for poor institutions that limit the degree of Central Bank independence) countries. Thus, in this case faster convergence would not coincide with higher market integration but would just be an unintended consequence of policies leading to higher inflation in initially poor countries with initially lower prices.

\subsection{Further results}

\subsubsection{Robustness analysis}

In addition to our baseline results, we provide a robustness analysis by considering three sets of exercises in the Online Appendix. First, we investigate the sensitivity of our findings to the assumption of exogeneity. Using lagged values as instrumental variables, Tables A10 and A11 provide some evidence that accounts for the endogeneity of threshold variables and regressors using a methodology proposed by Kourtellos, Stengos, and Tan (2016) who developed estimation and inference for threshold regression based on a control function approach. In general, our findings are substantially similar to our baseline results with a few notable differences. First, we note in Table A10 that when we control for endogeneity, the estimated threshold parameters tend to be much smaller in magnitude using initial prices as a threshold variable. While this implies a slightly different composition of the four regimes, we still find strong evidence of club convergence as $\beta$-coefficients always remain negative and strongly significant in all regimes ${ }^{22}$ Second, Table A11 shows that when we account

\footnotetext{
${ }^{22}$ That said, we should view this case with a grain of salt as the theory is not well developed for a model where the threshold variable is also a regressor, which is the case for the models that use initial prices as a
} 
for endogeneity, the $\beta$-coefficients (and hence the speeds of convergence) become smaller in magnitude in all models. Nevertheless, the $\beta$-coefficients remain always negative and strongly significant and therefore our main finding of club convergence remains robust to endogeneity. Third, when we account for endogeneity, we capture some additional interactions between the non-traded and traded channels for price convergence. For example, we find evidence of an interaction between distance and control of corruption in determining price differences. More precisely, Model 5 in Table A11 shows that once we account for the endogeneity, lower distance-related trade costs are conducive to price convergence only for countries with high control of corruption.

Second, we present threshold regression estimation results that use labor cost as a threshold variable in Tables A12 and A13 to investigate the role of labor cost in price club convergence. This variable, however, restricts the sample to 31 countries due to data unavailability. Overall, we find similar results, that is, we reject the null hypothesis of global $\beta$-convergence and find strong evidence for club convergence as in the baseline sample. Interestingly, the most theoretically appealing model is the one that splits the sample using distance (level 1) and labor cost (level 2). This model shows that within the low distance regime, countries with lower labor cost converge significantly faster than countries with high labor cost. This resembles the result for labor productivity in model 2 of Table 3, and is again suggestive of an interaction between the non-traded and traded channels via which price convergence occurs. Moreover, countries with low distance tend to converge faster than those with high distance from potential trade partners as long as they have lower labor cost. This result resembles the findings for labor productivity and initial income in models 2 and 3 from Table 3 and suggests that distance matters for trade and countries with lower labor costs might be more able to engage successfully in international trade. For example, countries with lower labor costs might face less political resistance in engaging in international trade than countries with high labor costs where some local players would lose out from engaging in international trade. We also find that the results from Models 5 and 7 in Table A13 that include labor cost as second threshold with control of corruption or initial prices as the respective first threshold variables resemble those from models 11 and 13 in Table 3 where initial prices enter as second threshold variable with initial productivity and initial income as the respective first threshold variables. Furthermore, the best model according to AIC that splits with labor cost (level 1) and democracy (level 2) exhibits similar results to the baseline findings discussed earlier regarding low democracy regime countries with low initial threshold variable. 
income or low initial labor productivity.

Third, in Tables A14 A16 of the Online Appendix, we present results that augment the baseline model with initial income, control of corruption and democracy to capture possible structural cross-country heterogeneity in addition to the country-, good-, and time-fixed effects included in the baseline model ${ }^{23}$ In general, we find that for factors related to the non-traded component of final prices, high values of initial income, labor productivity and democratic accountability hinder convergence, while high control of corruption reinforces convergence. Similarly, factors related to the traded component of final prices such as distance and initial prices have a suppressing effect on price convergence, i.e., countries with higher distance or higher initial prices tend to have lower convergence rates. ${ }^{24}$

In sum, our robustness analysis shows that the results are substantially similar to the baseline findings and hence, reaffirming the evidence for club convergence of retail prices due to the interaction of traded and non-traded factors.

\subsubsection{Classification of countries in convergence clubs}

Finally, we classify countries in convergence clubs using information from threshold regressions based on the baseline sample. In the four panels of Figure A4, we present the countries that belong to the various regimes using cross-plots between the two threshold variables $q_{1}$ and $q_{2}$ for four of the best models from Table 3 that include pairs of variables capturing respectively each of the two theoretically distinct components of final prices. These models include distance to capture the traded component in each case, and labor productivity, initial income or institutions to capture the non-traded component of prices. We consider Model 1 with $q_{1}=$ Democracy and $q_{2}=$ Distance in Panel (a); Model 2 with $q_{1}=$ Distance and $q_{2}=$ Initial Productivity in (b); Model 3 with $q_{1}=$ Distance and $q_{2}=$ Initial Income in (c); and Model 5 with $q_{1}=$ Control of Corruption and $q_{2}=$ Distance in Panel (d).

We calculate the share of years for which a country lies in one of the regimes and obtain frequencies of forming a regime for each country in each model. If the country lies in one of the regimes for more than $50 \%$ of the period, then it is classified in that regime. ${ }^{25}$ Results

\footnotetext{
${ }^{23}$ Initial productivity is not included due to multicollinearity issues. Distance is also not included since it is a country-specific variable and the model includes country fixed effects.

${ }^{24}$ We also estimate the augmented threshold regression models using the restricted sample of countries that include labor cost. The results are similar and can be found in Table A17 of the Online Appendix.

${ }^{25}$ There are four possibilities marked by different colors: blue denotes dismal conditions in both variables;
} 
verify at the country level the findings described in Table 3. The "best" regime, i.e., the regime with the most favorable economic conditions in both threshold variables, typically includes most of the European countries while the "bad" regime typically comprises Latin American and South East Asian countries. Other high income countries such as the US, Canada and Japan appear to belong to intermediate regimes only partly characterized by favorable conditions. Regimes exhibit substantial differences in convergence rates to their local long run equilibria. Panel (a) shows that countries with low democracy and low distance (in orange) appear to have the highest convergence pace. Panels (b) and (c) exhibit similar patterns, with countries (in green) with low distance and low initial income or productivity converging faster. Panel (d) shows that countries (in red) with high control of corruption and low distance converge faster than the rest.

These results imply a similar classification of countries to the one based on the nonlinear factor model in Table A3 ${ }^{26}$ Countries in the threshold regime described by the best conditions for more than $50 \%$ of models (Netherlands, Norway, Luxembourg, Switzerland, Sweden, Finland, Denmark, Austria, Germany, UK, Belgium, France, Spain and Australia) lie in the high-price club for more than $50 \%$ of our goods, and most countries that lie in the regime with worst conditions for more than 50\% of the models (Panama, Philippines, Guatemala, Thailand, Colombia, Peru, South Africa, Uruguay, Venezuela, Brazil, Paraguay and Kenya) lie in the medsium or low price clubs for more than $50 \%$ of the goods.

\section{Conclusion}

We have investigated the existence of convergence clubs in the cross-country mechanism of retail prices. First, we employed a nonlinear factor model distinguishing between economies that have converged and those that are converging. While we did not find evidence of global price convergence, we found strong evidence of convergence clubs. Second, we examined factors that determine price convergence clubs using a threshold regression

orange denotes bad conditions in $q_{1}$ but good conditions in $q_{2}$; green denotes good conditions in $q_{1}$ and bad $q_{2}$ conditions; and red denotes good conditions for both $q_{1}$ and $q_{2}$. Except for distance and initial prices, low values reflect bad economic conditions and high values good economic conditions. Thus, except for distance and initial prices, good conditions for $q_{i}$ correspond to the high $q_{i}$ regime obtained in the threshold model. Circles' size shows speed of convergence within each regime.

${ }^{26}$ This is shown in Table A18 in the appendix where we present country-specific frequencies of forming a regime based on the 36 estimated threshold regression models from Table 3 . We calculate the share of years for which the country lies a regime and obtain frequencies of forming each regime for each country in each model, which we use to compute the share of models for which a country lies in each regime. 
methodology allowing us to model the determinants of convergence clubs using observed threshold variables related to traded and non-traded factors, and to estimate regime-specific $\beta$-coefficients common within regimes. These regime-specific estimated coefficients map onto local rates of convergence consistent with a local law of one price. We find again strong evidence of club convergence, in line with our findings based on the nonlinear factor model. We reject the null of global $\beta$-convergence in favor of four convergence clubs arising due to factors associated with convergence in the non-traded and traded components of final prices acting as barriers to global price convergence.

Our findings point to interactions between the non-traded and traded channels via which price convergence occurs. First, countries in the low distance regime converge faster than those in the high distance one if they have low initial labor productivity, labor input costs or income. Second, countries with low initial productivity or labor input costs converge significantly faster than those in the respective high productivity or high labor cost regimes, if characterized by low average distance from trade partners. In the first instance, lower trade costs appear conducive to price convergence for countries that have the non-traded BalassaSamuelson catch up process operating given low initial labor productivity, labor cost or income levels. This can be due to the fact that at an early stage of development, industries stand to gain more from proximity to potential international trade partners whereas this does not matter much for industries in advanced economies producing highly differentiated products whose demand is not as sensitive to higher trade costs as compared to exports of less differentiated goods from less developed countries. In the second instance, being behind the technology frontier is more conducive to price convergence for countries with relatively small physical distance from potential trade partners that have easier access to international trade than for those in the high-distance regime. This implies that the growth advantage of initial economic backwardness is facilitated by the ability to trade more cheaply, pointing to trade as a key facilitator of economic growth which in turn leads to faster price convergence in initially lagging economies as these catch up to the frontier.

Our empirical analysis has uncovered a set of new facts to be taken into account in building open economy theory models to understand how trade and local factors interact to reinforce the process of economic integration across countries. Our results are relevant for the price convergence literature where no previous study had shown the presence of multiple regimes. They imply convergence is restricted to clubs within which countries share structural characteristics. Thus, clubs of countries define borders outside of which markets are segmented in a manner resembling that for national borders in the past. Finally, our 
detection of multiple regimes and factors that determine these, suggests there is much to be learned regarding club convergence by considering prices in addition to income.

\section{References}

Alessandria, G., 2009, Consumer Search, Price Dispersion and International Relative Price Fluctuations, International Economic Review 50, 803-829.

— , and J. P. Kaboski, 2011, Pricing-to-Market and the Failure of Absolute PPP, American Economic Journal: Macroeconomics 3, 91-127.

Andrade, P., and M. Zachariadis, 2016, Global Versus Local Shocks in Micro Price Dynamics, Journal of International Economics 98, 78-92.

Bernard, A.B, and S. N. Durlauf, 1995, Convergence in International Output, Journal of Applied Econometrics 10, 97-108.

— 1996, Interpreting Tests of the Convergence Hypothesis, Journal of Econometrics $71,161-174$.

Beyaert, A., and M. Camacho, 2008, TAR Panel Unit Root Tests and Real Convergence, Review of Development Economics 12, 668-681.

Brock, W., and C. Hommes, 1997, A Rational Route to Randomness, Econometrica 65, 1059-1095.

Burstein, A., and N. Jaimovich, 2012, Understanding Movements in Aggregate and ProductLevel Real Exchange Rates, unpublished manuscript Stanford and UCLA.

Caner, M., and B. Hansen, 2001, Threshold Autoregression with a Unit Root, Econometrica 69, 1555-1596.

Chen, L., S. Choi, and J. Devereux, 2008, Have Absolute Price Levels Converged for Developed Economies? The Evidence since 1870, The Review of Economics and Statistics 90, 29-36.

Choi, C.-Y., A. Murphy, and J. Wu, 2017, Segmentation of Consumer Markets in the U.S.: What Do Intercity Price Differences Tell Us?, Canadian Journal of Economics 50, 738777. 
Corsetti, G., and L. Dedola, 2005, Macroeconomics of International Price Discrimination, Journal of International Economics 67, 129-156.

Crucini, M., and M. Shintani, 2008, Persistence in Law of One Price Deviations: Evidence from Micro-Data, Journal of Monetary Economics 55, 629-644.

Crucini, M., C. Telmer, and M. Zachariadis, 2005, Understanding European Real Exchange Rates, American Economic Review 95, 724-738.

Dixit, A., 1989, Hysteresis, Import Penetration and Exhange Rate Pass-Through, Quarterly Journal of Economics 104, 205-28.

Dumas, B., 1992, Dynamic Equilibrium and the Real Exchange Rate in a Spatially Separated World, The Review of Financial Studies 5, 153-180.

Durlauf, S., and P. Johnson, 1995, Multiple Regimes and Cross-Country Growth Behavior, Journal of Applied Econometrics 10, 365-384.

Durlauf, S., A. Kourtellos, and A. Minkin, 2001, The Local Solow Growth Model, European Economic Review 45, 928-940.

Evans, P., and G. Karras, 1996, Convergence Revisited, Journal of Monetary Economics 37, 249-265.

Glushenkova, M., and M. Zachariadis, 2016, Understanding post-Euro Law-of-One-Price Deviations, Journal of Money, Credit and Banking 48, 1073-1111.

Gopinath, G., 2016, The International Price System, Jackson Hole Symposium Proceedings.

Hansen, B., 1999, Threshold Effects in Non-dynamic Panels: Estimation, Testing, and Inference, Journal of Econometrics 93, 345-368.

Hansen, B. E., 1996, Inference When a Nuisance Parameter Is Not Identified Under the Null Hypothesis, Econometrica 64, 413-430.

Hobijn, B., and P. H. Franses, 2000, Asymptotically Perfect and Relative Convergence of Productivity, Journal of Applied Econometrics 15, 59-81.

Imbs, J., H. Mumtaz, M. Ravn, and H. Rey, 2005, PPP Strikes Back: Aggregation and the Real Exchange Rate, Quarterly Journal of Economics 120, 1-44. 
Kourtellos, A., T. Stengos, and C. M. Tan, 2016, Structural Threshold Regression, Econometric Theory 32, 827-860.

Krugman, P. R., 1989, Exchange Rate Instability (MIT: Cambridge).

Midrigan, V., 2007, International Price Dispersion in State-Dependent Pricing Models, Journal of Monetary Economics 54, 2231-2250.

Obstfeld, M., and A.M. Taylor, 1997, Nonlinear Aspects of Goods-Market Arbitrage and Adjustment: Heckschers Commodity Points Revisited, Journal of Japanese and International Economics 11, 411-479.

O'Connell, P.G.J., and S.-J. Wei, 2002, The Bigger They Are, the Harder They Fall: Retail Price Differences across US Cities, Journal of International Economics 56, 21-53.

Phillips, P., and D. Sul, 2007, Transition Modeling and Econometric Convergence Tests, Econometrica 75, 1771-1855.

— 2009, Economic Transition and Growth, Journal of Applied Econometrics 24, 11531185.

Sercu, P., R. Uppal, and C. Van Hulle, 1995, The Exchange Rate in the Presence of Transaction Costs: Implications for Tests of Purchasing Power Parity, The Journal of Finance 50, 1309-1319.

Tan, C., 2010, No One True Path: Uncovering the Interplay Between Geography, Institutions, and Fractionalization in Economic Development, Journal of Applied Econometrics 25, 1100-1127.

Taylor, M., D. Peel, and L. Sarno, 2001, Nonlinear Mean-Reversion in Real Exchange Rates: Toward a Solution to the Purchasing Power Parity Puzzles, International Economic Review $42,1015-1042$. 


\section{Figure 1: Transition Paths for Clubs by Industry}

This figure shows transition curves for each of the three clubs defined at the industry level. The relative transition curve for each club is calculated as the average transition coefficient across countries that form the club for each industry.

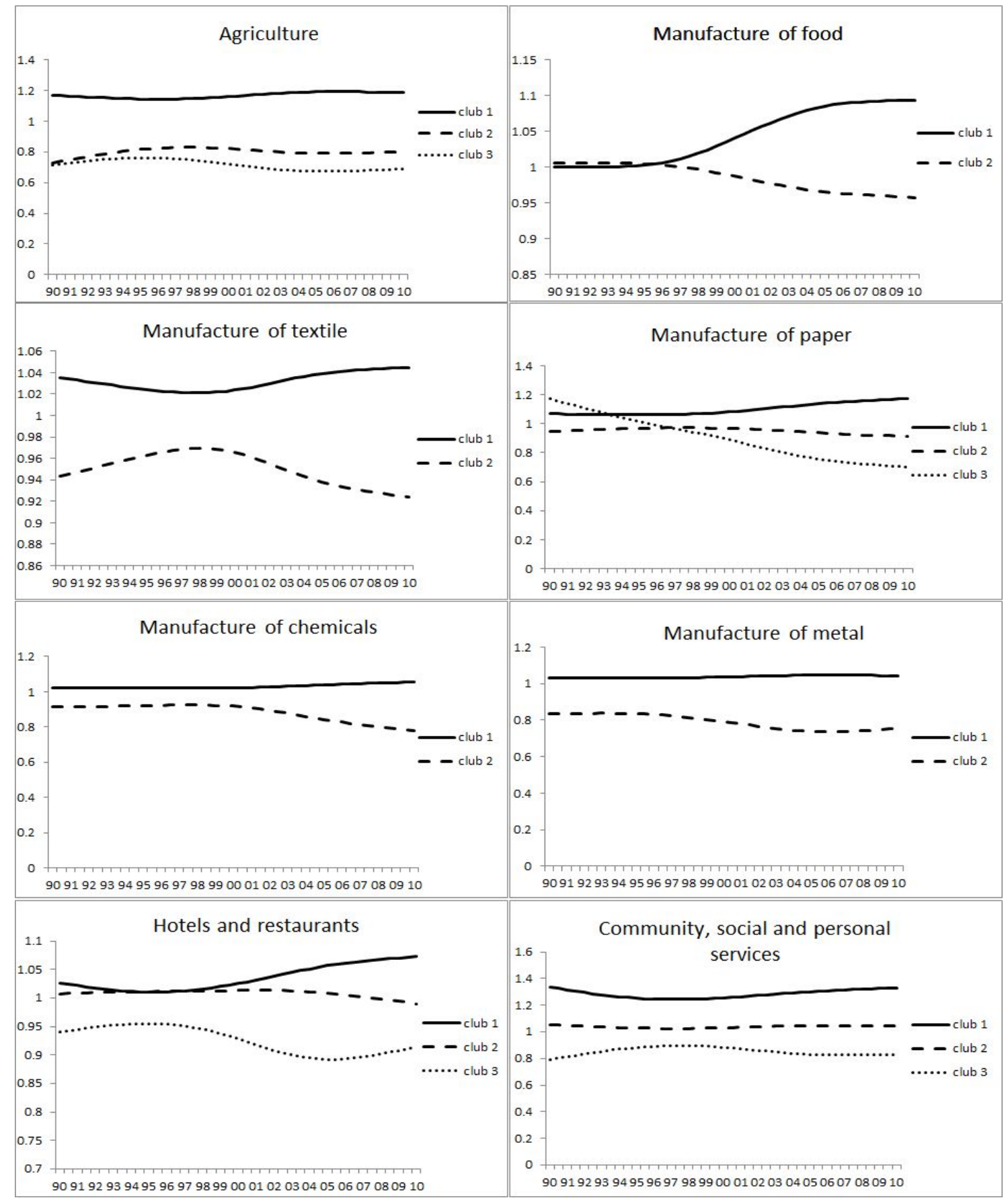




\section{Table 1: Convergence Coefficients at the Industry Level}

\section{Industry}

Agriculture

Food

Textile

Paper products

Chemicals

Metal products

Hotels and restaurants

Other services
Convergence Coefficient
Global Club 1 Club 2 Club 3 Divergent group

$\begin{array}{lrrrr}-0.752^{*} & 0.163 & 0.707 & 0.000 & -0.653^{* *} \\ -0.296^{*} & 0.540 & -0.049 & - & - \\ -1.940^{*} & -0.134 & 0.503 & - & -1.406^{*} \\ -1.119^{*} & 0.771 & -0.119 & 4.946 & - \\ -0.407^{*} & 0.101 & 0.117 & - & - \\ -0.385^{*} & 0.246 & 0.117 & - & - \\ -0.927^{*} & 0.184 & -0.075 & 0.165 & - \\ -0.736^{*} & 0.125 & 0.100 & 0.142 & \end{array}$

Notes: This table presents estimates of the convergence coefficient $\lambda_{1 j}$ in equation (2) and convergence tests using the $\log \mathrm{t}$ test of Phillips and Sul (2009) at the industry level of analysis. Column 2 presents the global convergence coefficients. The next three columns present estimates of the three club convergence coefficients based on the procedure described in Section 3.3. The last column presents coefficient estimates of the divergent group. ${ }^{*},{ }^{*} *$ refer to the significance level of $1 \%$ and $5 \%$, respectively, at which the null of convergence, $H_{0}: \lambda_{1 j} \geq 0$ is rejected. 
Table 2: Threshold Estimation and Testing

Threshold variables Level $1\left(q_{1}\right) \quad$ Level $2\left(q_{2}\right)$
Threshold point and interval estimates

Two-regime TR model Four-regime TR mode

AIC

\begin{tabular}{|c|c|c|c|c|c|c|}
\hline & \multirow{2}{*}{\multicolumn{4}{|c|}{ High $q_{1}$}} & \\
\hline & & & & & & \\
\hline $\begin{array}{l}\text { Threshold } \\
\text { value }\end{array}$ & $95 \% \mathrm{CI}$ & $\begin{array}{l}\text { Threshold } \\
\text { value }\end{array}$ & $95 \% \mathrm{CI}$ & $\begin{array}{c}\text { Threshold } \\
\text { value }\end{array}$ & $95 \% \mathrm{CI}$ & \\
\hline $8.798 * \dagger$ & {$[8.717,9.246]$} & $9.944 * \dagger$ & {$[9.658,10.498]$} & $8.955 * \dagger$ & {$[8.157,10.120]$} & -3.502 \\
\hline $8.798 * \dagger$ & {$[8.717,9.246]$} & $10.861^{*} \dagger$ & {$[10.558,11.177]$} & $10.127^{*} \dagger$ & {$[9.179,10.935]$} & -3.503 \\
\hline $8.798 * \dagger$ & {$[8.717,9.246]$} & $8.727^{*} \dagger$ & {$[8.710,8.774]$} & $9.243 * \dagger$ & {$[9.058,9.293]$} & -3.500 \\
\hline $8.798 * \dagger$ & {$[8.717,9.246]$} & $4.292 * \dagger$ & {$[3.000,5.917]$} & $4.000 * \dagger$ & {$[2.000,4.917]$} & -3.497 \\
\hline $8.798 * \dagger$ & {$[8.717,9.246]$} & $\begin{array}{l}4.292 * \top \\
5.375 * \dagger\end{array}$ & {$[5.000,5.917]$} & $\begin{array}{l}4.000 * \top \\
5.208 * \dagger\end{array}$ & {$[3.000,5.917]$} & $\begin{array}{l}-3.497 \\
-3.502 \\
\end{array}$ \\
\hline $8.798 * \dagger$ & {$[8.717,9.246]$} & $1.223 * * \dagger$ & {$[0.312,4.324]$} & $1.655^{* * \dagger}$ & {$[-0.100,4.037]$} & -3.498 \\
\hline $1.656^{* * \dagger} \dagger$ & {$[0.089,4.183]$} & $9.521 * \dagger$ & {$[8.376,10.333]$} & $9.244^{*} \dagger$ & {$[8.564,10.418]$} & -3.493 \\
\hline $1.656^{* * \dagger} \dagger$ & {$[0.089,4.183]$} & $10.471^{*} \dagger$ & {$[9.475,11.115]$} & $10.720 * \dagger$ & {$[9.621,11.144]$} & -3.493 \\
\hline $1.656^{* * \dagger}$ & {$[0.089,4.183]$} & $8.798 * \dagger$ & {$[8.719,9.246]$} & $8.798^{*} \dagger$ & {$[8.714,9.246]$} & -3.498 \\
\hline $1.656^{* * \dagger}+$ & {$[0.089,4.183]$} & $3.083 * \dagger$ & {$[2.000,5.042]$} & $3.083 * \dagger$ & {$[2.375,5.417]$} & -3.492 \\
\hline $1.656^{* * \dagger}+$ & {$[0.089,4.183]$} & $5.000 * \dagger$ & {$[3.667,5.917]$} & $5.000 * \dagger$ & {$[4.000,5.917]$} & -3.490 \\
\hline $1.656^{* * \dagger} \dagger$ & {$[0.089,4.183]$} & $-0.027^{* *} \dagger$ & {$[-0.340,1.287]$} & $3.672^{* * *} \dagger$ & {$[2.050,5.316]$} & -3.488 \\
\hline $9.521 * \dagger$ & {$[8.457,10.380]$} & $8.973 * \dagger$ & {$[8.077,9.108]$} & $10.065 * \dagger$ & {$[9.877,10.527]$} & -3.495 \\
\hline $9.521 * \dagger$ & {$[8.457,10.380]$} & $\begin{array}{l}0.910 \\
9.669\end{array}$ & {$[9.018,10.103]$} & $10.892 * \dagger$ & {$[10.815,11.210]$} & -3.497 \\
\hline $9.521 * \dagger$ & {$[8.457,10.380]$} & $9.169^{*}$ & {$[9.058,9.246]$} & $8.789 * \dagger$ & {$[8.712,8.973]$} & -3.498 \\
\hline $\begin{array}{l}9.521 * \dagger \\
9.521\end{array}$ & {$[8.457,10.380]$} & $2.000 * \dagger$ & {$[2.000,3.833]$} & $\begin{array}{l}0.109 * \dagger \\
4.792 * \dagger\end{array}$ & {$[3.792,5.917]$} & $\begin{array}{l}-3.490 \\
-3.495\end{array}$ \\
\hline $9.521 * \dagger$ & {$[8.457,10.380]$} & $4.333^{*} \dagger$ & {$[3.000,4.917]$} & $5.000 * \dagger$ & {$[5.000,5.917]$} & -3.498 \\
\hline $9.521 * \dagger$ & {$[8.457,10.380]$} & $-0.047^{* *} \dagger$ & {$[-0.194,3.949]$} & $2.220 * * \dagger$ & {$[0.344,4.368]$} & -3.496 \\
\hline $10.471^{*} \dagger$ & {$[9.545,11.131]$} & $8.973 * \dagger$ & {$[8.077,9.122]$} & $10.065 * \dagger$ & {$[9.879,10.527]$} & -3.494 \\
\hline $10.471 * \dagger$ & {$[9.545,11.131]$} & $10.095 * \dagger$ & {$[9.018,10.112]$} & $10.892 * \dagger$ & {$[10.823,11.210]$} & -3.496 \\
\hline $10.471 * \dagger$ & {$[9.545,11.131]$} & $9.169 * \dagger$ & {$[9.058,9.246]$} & $8.789 * \dagger$ & {$[8.712,8.959]$} & -3.499 \\
\hline $10.471 * \dagger$ & {$[9.545,11.131]$} & 2.000 & {$[2.000,3.833]$} & $4.833 * \dagger$ & {$[4.000,5.917]$} & -3.496 \\
\hline $10.471^{* \dagger}+$ & {$[9.545,11.131]$} & $4.333 * \dagger$ & {$[3.000,5.000]$} & $5.000 * \dagger$ & {$[5.000,5.917]$} & $\begin{array}{l}-0.490 \\
-3.499\end{array}$ \\
\hline $10.471^{*} \dagger$ & {$[9.545,11.131]$} & $-0.067 * * \dagger$ & {$[-0.190,3.949]$} & $2.222 * * \dagger$ & {$[0.342,4.364]$} & -3.497 \\
\hline $3.083 * \dagger$ & {$[2.000,5.417]$} & 8.59 & {$[8.0$} & 10.0 & 10. & -3.496 \\
\hline 3.08 & {$[2.000,5.417]$} & 9.90 & {$[9.009,10.285]$} & 10.8 & {$[10.536,11.200]$} & -3.499 \\
\hline 3.08 & {$[2.000,5.417]$} & 9.0 & {$[8.798,9.243]$} & $8.7 !$ & {$[8.712,9.243]$} & -3.500 \\
\hline 3.083 & {$[2.000,5.417]$} & 2.0 & {$[2.000,2.9$} & 4.9 & {$[4.000,5.917]$} & -3.492 \\
\hline $3.083 * \dagger$ & {$[2.000,5.417]$} & $4.333 * \dagger$ & {$[3.000,5.458]$} & $5.000 * \dagger$ & {$[5.000,5.917]$} & -3.502 \\
\hline $3.083 * \dagger$ & {$[2.000,5.417]$} & $1.767^{* * \dagger}$ & {$[-0.134,4.032]$} & $1.223 * * \dagger$ & {$[0.260,4.288]$} & -3.493 \\
\hline $5.000 * \dagger$ & {$[4.000,5.917]$} & 9.190 & {$[8.142,9.88$} & $9.686 * \dagger$ & {$[9.686,10.527]$} & -3.496 \\
\hline $5.000 * \dagger$ & {$[4.000,5.917]$} & $10.929^{*} \dagger$ & {$[9.177,10.929]$} & $10.793^{*} \dagger$ & {$[10.558,11.206]$} & $\begin{array}{l}-3.490 \\
-3.494\end{array}$ \\
\hline $5.000 * \dagger$ & {$[4.000,5.917]$} & $9.064 * \dagger$ & {$[8.754,9.249]$} & $8.789 * \dagger$ & {$[8.712,9.058]$} & -3.512 \\
\hline $5.000 * \dagger$ & {$[4.000,5.917]$} & $3.083^{*} \dagger$ & {$[2.000,3.833]$} & $5.417 * \dagger$ & {$[3.500,5.917]$} & -3.495 \\
\hline $5.000 * \dagger$ & {$[4.000,5.917]$} & $3.250 * \dagger$ & {$[3.000,4.917]$} & 5.667 & {$[5.667,5.917]$} & -3.495 \\
\hline $5.000 * \dagger$ & {$[4.000,5.917]$} & $-0.036^{* *} \dagger$ & {$[-0.134,4.008]$} & $2.220 * * \dagger$ & {$[0.301,4.346]$} & -3.494 \\
\hline
\end{tabular}

Notes: This table presents threshold estimates at the good level of analysis. In the first six columns, we report the corresponding threshold estimate and its $95 \%$ confidence interval for the first and second level of sample splitting respectively. The last column reports the Akaike information criterion (AIC). Each row presents one model with two specific threshold variables. All models estimate equation 3. with the following vector of regressors $x_{i j t}=\left(d_{i}^{\prime}, d_{j}^{\prime}, d_{t}^{\prime}, p_{i j t-1}\right)^{\prime}$, where $d_{i}, d_{j}$ and $d_{t}$ are country, good and time dummies, and $p_{i j t-1}$ is initial price level. $*, * *, * * *$, refer to the significance level of $1 \%, 5 \%$, and $10 \%$, respectively, at which the null of linearity is rejected. $\dagger$ - reject the null of a unit root at the $1 \%$ significance level based on the threshold autoregressive unit root test introduced by Caner and Hansen [2001] and extended for the panel-data model by Beyaert and Camacho 2008). Results for both tests are calculated using standard heteroscedasticity and autocorrelation corrected estimators. We estimate threshold regressions using a panel of semiannual prices for 96 goods from 1990 to 2010 across 38 countries and end up with 137240 observations. 


\section{Table 3: Club Convergence: Evidence from Threshold Regressions}

\begin{tabular}{|c|c|c|c|c|c|c|c|c|c|c|c|c|}
\hline & \multirow{3}{*}{ Model } & \multicolumn{2}{|c|}{ Threshold Variable } & \multicolumn{4}{|c|}{$\beta$-coefficients } & \multicolumn{4}{|c|}{ Speed of convergence } & \multirow[t]{3}{*}{ AIC } \\
\hline & & \multirow[t]{2}{*}{ Level $1\left(q_{1}\right)$} & \multirow[t]{2}{*}{ Level $2\left(q_{2}\right)$} & \multicolumn{2}{|c|}{ low $q_{1}$} & \multicolumn{2}{|c|}{ high $q_{1}$} & \multicolumn{2}{|c|}{ low $q_{1}$} & \multicolumn{2}{|c|}{ high $q_{1}$} & \\
\hline & & & & low $q_{2}$ & high $q_{2}$ & low $q_{2}$ & high $q_{2}$ & low $q_{2}$ & high $q_{2}$ & low $q_{2}$ & high $q_{2}$ & \\
\hline & 1 & Democracy & Distance & $-0.139^{*} \dagger$ & $-0.081 \dagger \dagger$ & -0.066 & -0.067 & 0.150 & 0.085 & 0.068 & 0.069 & -3.512 \\
\hline & 2 & Distance & Initial productivity & $-0.146^{*} \dagger$ & -0.065 & -0.083 & -0.070 & 0.158 & 0.067 & 0.087 & 0.072 & -3.503 \\
\hline & 3 & Distance & Initial income & $-0.140^{*} \dagger$ & -0.063 & $-0.087^{*}$ & -0.067 & 0.151 & 0.065 & 0.090 & 0.070 & -3.502 \\
\hline & 4 & Control of corruption & Democracy & $-0.098 * \dagger$ & $-0.057 \dagger$ & $-0.146^{*}$ & -0.070 & 0.103 & 0.059 & 0.158 & 0.072 & -3.502 \\
\hline & 5 & Control of corruption & Distance & $-0.079 \dagger \dagger$ & $-0.080 \dagger \dagger \dagger$ & -0.092 & -0.089 & 0.082 & 0.084 & 0.097 & 0.093 & -3.500 \\
\hline & 6 & Distance & Distance & $-0.068^{*}$ & $-0.116 \dagger$ & $-0.084 * * *$ & -0.070 & 0.071 & 0.123 & 0.088 & 0.072 & -3.500 \\
\hline & 7 & Control of corruption & Initial productivity & $-0.078^{*} \dagger$ & $-0.083 \dagger$ & $-0.138^{*}$ & -0.060 & 0.081 & 0.086 & 0.149 & 0.062 & -3.499 \\
\hline & 8 & Initial productivity & Democracy & $-0.110^{*} \dagger$ & $-0.080 \dagger$ & -0.071 & -0.069 & 0.117 & 0.083 & 0.073 & 0.071 & -3.499 \\
\hline & 9 & Initial income & Democracy & $-0.111^{*} \dagger$ & $-0.077 \dagger$ & -0.066 & -0.070 & 0.118 & 0.080 & 0.068 & 0.073 & -3.498 \\
\hline & 10 & Distance & Initial prices & $-0.138^{*} \dagger$ & $-0.069 \dagger \dagger$ & $-0.097^{*}$ & -0.062 & 0.149 & 0.071 & 0.102 & 0.063 & -3.498 \\
\hline & 11 & Initial productivity & Initial prices & $-0.153^{*} \dagger$ & $-0.082 \dagger$ & $-0.088^{*}$ & -0.049 & 0.166 & 0.085 & 0.092 & 0.050 & -3.497 \\
\hline & 12 & Initial income & Initial productivity & $-0.084^{*} \dagger$ & $-0.113 \dagger$ & $-0.102^{*}$ & -0.058 & 0.088 & 0.120 & 0.108 & 0.060 & -3.497 \\
\hline & 13 & Initial income & Initial prices & $-0.153^{*} \dagger$ & $-0.081 \dagger$ & $-0.088^{*}$ & -0.050 & 0.166 & 0.084 & 0.092 & 0.051 & -3.496 \\
\hline \multirow{8}{*}{ ల్ర } & 14 & Control of corruption & Initial income & $-0.084 \dagger$ & $-0.075 \dagger$ & $-0.134^{*}$ & -0.056 & 0.087 & 0.078 & 0.144 & 0.058 & -3.496 \\
\hline & 15 & Initial productivity & Initial productivity & -0.098 & $-0.087 \dagger$ & $-0.102^{*}$ & -0.058 & 0.104 & 0.091 & 0.108 & 0.060 & -3.496 \\
\hline & 16 & Initial income & Initial income & $-0.103^{*}$ & -0.072 & $-0.093^{*}$ & -0.054 & 0.109 & 0.075 & 0.097 & 0.055 & -3.495 \\
\hline & 17 & Democracy & Democracy & $-0.129 * \dagger$ & $-0.085 \dagger$ & \multicolumn{2}{|c|}{-0.067} & 0.138 & 0.089 & \multicolumn{2}{|c|}{0.069} & -3.495 \\
\hline & 18 & Democracy & Initial prices & $-0.154^{*} \dagger$ & $-0.084 \dagger$ & $-0.086^{*}$ & -0.049 & 0.167 & 0.087 & 0.089 & 0.050 & -3.494 \\
\hline & 19 & Control of corruption & Initial prices & $-0.093^{*} \dagger$ & -0.064 & $-0.136^{*}$ & -0.067 & 0.097 & 0.066 & 0.146 & 0.069 & -3.493 \\
\hline & 20 & Control of corruption & Control of corruption & $-0.064^{*} \dagger \dagger$ & $-0.090 \dagger \dagger \dagger$ & -0.090 & -0.092 & 0.066 & 0.094 & 0.095 & 0.097 & -3.492 \\
\hline & 21 & Initial prices & Initial prices & $-0.144 * \dagger$ & $-0.087 \dagger$ & -0.067 & -0.063 & 0.155 & 0.091 & 0.070 & 0.065 & -3.488 \\
\hline
\end{tabular}

Notes: This table presents coefficient estimates for the initial price level in the threshold regression models using threshold variables $q_{1}$ and $q_{2}$ at the first and second levels of sample splitting, respectively. All the coefficients are estimated to be significant at the $1 \%$ level. ${ }^{*}, * *, * * *$ - reject the null that the coefficient for the low $q_{2}$ equals the respective high $q_{2}$ coefficient within the same $q_{1}$ regime at the $1 \%, 5 \%$, and $10 \%$ level of significance, respectively. $\dagger, \dagger \dagger, \dagger \dagger \dagger$ - reject the null that coefficient for the low $q_{1}$ equals the respective coefficient for high $q_{1}$ at the $1 \%, 5 \%$, and $10 \%$ level of significance, respectively. Each row presents one model with two specific threshold variables. All models estimate equation 3 . with the following vector of regressors $x_{i j t}=\left(d_{i}^{\prime}, d_{j}^{\prime}, d_{t}^{\prime}, p_{i j t-1}\right)^{\prime}$, where $d_{i}, d_{j}$ and $d_{t}$ are country, good and time dummies, and $p_{i j t-1}$ is initial price level. The first four columns present beta coefficients for the four regimes, followed by the respective speed of convergence for the four regimes in the next four columns, and the AIC value for each model in the last column. The models are ordered by AIC. We estimate threshold regressions using a panel of semiannual prices for 96 goods from 1990 to 2010 across 38 countries and end up with 137240 observations. 